\title{
Plasma concentrations of dietary and nondietary antioxidants are low in severe
} asthma

\author{
N.L.A. Misso**\#, J. Brooks-Wildhaber*, S. Ray*, H. Vally* and P.J. Thompson*,\#
}

ABSTRACT: Low antioxidant levels and oxidative stress due to airway inflammation may be important determinants of asthma severity. The objective of the present study was to determine whether lower antioxidant intake and plasma antioxidant concentrations are associated with more severe asthma.

Dietary antioxidant intakes and asthma severity were assessed using questionnaires, and plasma concentrations of ascorbic acid, vitamin E, carotenoids, bilirubin, albumin, uric acid and total antioxidant status were measured in 53 mild-to-moderate and 28 severe asthmatic patients and in $\mathbf{4 3}$ nonasthmatic subjects.

Vitamin $\mathbf{C}$ and carotene intakes were lower in males than females and were particularly low in males with severe asthma. Plasma ascorbic acid was lower in severe $(31.9 \pm 3.6 \mu \mathrm{M})$ compared with mild-to-moderate asthmatic $(52.3 \pm 2.6)$ or control subjects $(52.7 \pm 2.9)$. Low plasma ascorbic acid (odds ratio (OR) 0.93; 95\% confidence interval (CI) 0.9-0.97), bilirubin (OR 0.69; 95\% $\mathrm{Cl} 0.51-$ 0.93) and increased plasma cholesterol (OR 1.98; 95\% Cl 1.05-3.73) were independently associated with severe asthma. Albumin was positively and cholesterol negatively correlated with lung function.

Low plasma concentrations of specific antioxidants are associated with more severe asthma. Increased antioxidant intake may help reduce the burden of severe asthma, particularly in males.

KEYWORDS: Albumin, antioxidants, asthma severity, bilirubin, dietary intake, vitamin C

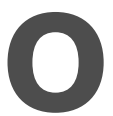
ne of the factors contributing to more severe asthma may be an increased susceptibility to the effects of reactive oxygen species (ROS) generated by inflammatory cells recruited into the lungs [1]. The potentially damaging effects of oxidative stress are normally limited by antioxidants that scavenge ROS in the respiratory tract lining fluid [2]. However, low dietary intakes of antioxidant vitamins or reduced synthesis of nondietary antioxidants such as albumin, bilirubin, glutathione peroxidase and uric acid are likely to result in an oxidant-antioxidant imbalance that exacerbates chronic inflammation and tissue damage in severe asthma [1].

The increasing prevalence of asthma in Western societies has been associated with dietary changes that have led to decreased intakes of vitamins A, C and E $[3,4]$. Epidemiological studies have shown associations between low dietary antioxidant intakes, reduced lung function and increased respiratory symptoms [5-8]. While studies of associations between dietary antioxidant intake and respiratory disease are clearly important, measurements of blood or tissue antioxidant levels are also necessary for a better understanding of the potential influences of disease severity, treatments and environmental and lifestyle factors other than diet. Previous studies have shown lower total antioxidant capacity in patients with asthma [9], lower plasma concentrations of ascorbic acid and $\beta$ carotene in subjects with self-reported wheeze [10], and low glutathione peroxidase activity and serum selenium concentrations in asthmatic patients have previously been observed [11].

Although dietary factors and antioxidants are likely to influence asthma severity [11, 12], the clinical characteristics of the patients have not been well defined in many previous studies, precluding any assessment of the relationship between disease severity, diet and antioxidant levels. Importantly, possible associations between asthma severity and nondietary antioxidants such as albumin, bilirubin and uric acid have not been investigated. Therefore, the
AFFILIATIONS

*Asthma and Allergy Research Institute, Nedlands,

\#Centre for Asthma, Allergy and Respiratory Research, The University of Western Australia, Perth, Australia.

CORRESPONDENCE

N.L.A. Misso

Asthma \& Allergy Research Institute Ground Floor

E Block

Sir Charles Gairdner Hospital

Nedlands

WA 6009

Australia

Fax: 61893462816

E-mail: nmisso@aari.uwa.edu.au

Received:

January 182005

Accepted after revision:

May 032005 
aim of the present study was to compare dietary antioxidant intakes, the plasma concentrations of specific dietary and nondietary antioxidants and plasma total antioxidant capacity in large groups of carefully defined mild-tomoderate or severe asthmatic patients and healthy control subjects.

\section{METHODS \\ Subjects}

Asthmatic patients were recruited from the Asthma and Allergy Research Institute and Sir Charles Gairdner Hospital (both Nedlands, Western Australia) databases and the study was approved by the Human Research Ethics Committee, at Sir Charles Gairdner Hospital (Perth, Australia). These institutions treat patients with mild to severe asthma from the entire Perth metropolitan area. All patients had a previous physician diagnosis of asthma and were categorised as having severe asthma if they met at least four of seven criteria, which were modifications of the National Asthma Education and Prevention Program, Expert Panel Report II guidelines [13]. The criteria were as follows: 1) $\beta_{2}$-agonist use $\geqslant 3$ times per day, most days in the previous 3 months; 2) regular inhaled corticosteroid use $\geqslant 1,000 \mu \mathrm{g} \cdot \mathrm{day}^{-1}$ in the previous 3 months; 3 ) use of oral corticosteroids within the last 12 months; 4 ) hospital admission for asthma in the previous 12 months; 5) $\geqslant 3$ unplanned visits to a general practitioner in the previous 12 months due to asthma exacerbations; 6) daily asthma symptoms including cough, wheeze, chest tightness and breathlessness when asthma was unstable in the previous 3 months; and 7) nocturnal awakening due to asthma symptoms $\geqslant 2$ times per week in the last 3 months. All patients were studied at a time when their asthma was stable and the severity categorisation was designed to reflect their background longterm baseline asthma status.

In order to recruit a nonasthmatic control subjects from a comparable population, letters inviting subjects to participate were mailed to addresses randomly selected from the Perth metropolitan telephone directory. Control subjects completed a brief questionnaire relating to their general health status. Recruitment of asthmatic and control subjects was completed within 6 months. The smoking status of all subjects was ascertained, forced expiratory volume in one second (FEV1) was measured and atopic status was assessed by skin-prick testing to six common aeroallergens. A wheal diameter $\geqslant 3 \mathrm{~mm}$ was considered a positive reaction. Since asthma severity and diet are both associated with socioeconomic status (SES), the subjects were categorised into low, middle and high SES groups using residential postcodes, which have previously been shown to be a reasonably reliable indicator of SES in Australia [14]. Table 1 shows the demographic characteristics of the patients and control subjects and current drug usage for the asthma patients is presented in table 2 .

\section{Food frequency questionnaire}

A validated semi-quantitative food frequency questionnaire (Questan; CSIRO Division of Human Nutrition, Adelaide, Australia) [15] was administered by a trained dietician (J. Brooks-Wildhaber). The intake of specific antioxidants was computed from the reported frequency of consumption of specified units of food and drink and published data on the

\begin{tabular}{|c|c|c|c|}
\hline \multirow[t]{2}{*}{ TABLE 1} & \multicolumn{3}{|c|}{$\begin{array}{l}\text { Characteristics of asthmatic patients and control } \\
\text { subjects }\end{array}$} \\
\hline & $\begin{array}{l}\text { Control } \\
\text { subjects }\end{array}$ & $\begin{array}{l}\text { Mild-to-moderate } \\
\text { asthmatic } \\
\text { patients }\end{array}$ & $\begin{array}{c}\text { Severe } \\
\text { asthmatic } \\
\text { patients }\end{array}$ \\
\hline Subjects $n$ & 43 & 53 & 28 \\
\hline Age yrs, mean \pm SD & $46.7 \pm 10.8$ & $46.8 \pm 13.6$ & $46.5 \pm 11.9$ \\
\hline Female & $24(56)$ & $34(64)$ & $20(71)$ \\
\hline$B M I \mathbf{k g} \cdot \mathbf{m}^{-2}$ & $25.0 \pm 0.7$ & $25.3 \pm 0.8$ & $30.1 \pm 1.6^{\#}$ \\
\hline $\begin{array}{l}\text { Total fat intake } \\
\% \text { of energy }\end{array}$ & $30.1 \pm 1.1$ & $31.4 \pm 0.9$ & $33.6 \pm 1.0^{\star}$ \\
\hline Atopic** & $24(56)$ & $47(89)$ & $21(75)$ \\
\hline FEV $1 \%$ predicted & $102.1 \pm 2.0$ & $87.7 \pm 2.2$ & $67.4 \pm 4.1$ \\
\hline Current smoker & $5(11.6)$ & $1(1.9)$ & $4(14.3)$ \\
\hline $\begin{array}{l}\text { Taking vitamin } \\
\text { supplements }\end{array}$ & $20(46.5)$ & $25(47.2)$ & $6(21.4)$ \\
\hline \multicolumn{4}{|l|}{$\begin{array}{l}\text { Socioeconomic } \\
\text { status }\end{array}$} \\
\hline High & $29(67)$ & $36(68)$ & $10(37)$ \\
\hline Middle & $6(14)$ & $11(21)$ & $10(37)$ \\
\hline Low & $8(19)$ & $6(11)$ & $7(26)$ \\
\hline
\end{tabular}

Data are presented as mean $\pm \mathrm{SEM}, \mathrm{n}$ or $\mathrm{n}(\%)$ unless otherwise stated. BMI: body mass index; FEV1: forced expiratory volume in one second. *: $p<0.05$ compared with control subjects; **: $p<0.01 ; \#: p=0.002$ compared with control subjects and mild-to-moderate asthmatics; $": p<0.05$ by Chi-squared analysis. FEV1 differed significantly among the three groups, $p<0.001$.

TABLE 2 Current drug usage in asthmatic patients

\begin{tabular}{|c|c|c|}
\hline & $\begin{array}{l}\text { Mild-to-moderate } \\
\text { asthmatic } \\
\text { patients }\end{array}$ & $\begin{array}{c}\text { Severe } \\
\text { asthmatic } \\
\text { patients }\end{array}$ \\
\hline Oral corticosteroid ${ }^{\#}$ & 0 & $9(32)^{\star \star \star}$ \\
\hline Inhaled corticosteroid & $35(66)$ & $25(89)^{*}$ \\
\hline Inhaled corticosteroid dose $\mu \mathrm{g} \cdot$ day $^{-19}$ & $933.7 \pm 130.8$ & $2,380 \pm 222.4^{+}$ \\
\hline Short acting $\beta_{2}$-agonist & $34(64)$ & $27(96)^{\star}$ \\
\hline Long acting $\beta_{2}$-agonist & $8(15)$ & $18(64)^{\star \star \star}$ \\
\hline Anti-cholinergic & $1(2)$ & $9(32)^{\star \star \star}$ \\
\hline Theophylline & $2(4)$ & $7(25)^{*}$ \\
\hline Cromone & $1(2)$ & $4(14)$ \\
\hline Hospital admissions ever & $22(42)$ & $26(93)^{\star \star \star}$ \\
\hline Hospital admissions past year & $2(4)$ & $13(46)^{\star \star \star}$ \\
\hline
\end{tabular}

Data are presented as mean \pm SEM or $n$ (\%) unless otherwise stated. \#: oral corticosteroid use at time of blood sampling; ": beclomethasone equivalent dose. ${ }^{*}: p<0.05,{ }^{* * *}: p<0.001$ by Chi-squared analysis; ${ }^{+}: p<0.001$ compared with mild-to-moderate asthmatics by an unpaired t-test.

antioxidant contents of these foods. Information on the doses and antioxidant contents of the variety of vitamin supplements consumed by study participants was inadequate to permit accurate quantification. Therefore, antioxidant intakes derived from supplements were excluded from the estimates of dietary antioxidant intake. However, major findings were confirmed 
by performing sub-analyses after exclusion of vitamin supplement users.

\section{Plasma antioxidant measurements}

Fasting blood samples were taken for measurement of ascorbic acid, $\alpha$-tocopherol, retinol, $\beta$-carotene, $\alpha$-carotene, lycopene, bilirubin, uric acid, albumin and total cholesterol in the Dept of Clinical Biochemistry, PathCentre (Nedlands, Western Australia). Retinol, $\alpha$-tocopherol and carotenoids were extracted into hexane and analysed by reverse-phase HPLC with UV detection at 325, 280, 474 and $456 \mathrm{~nm}$, using $\alpha$ tocopherol acetate as an internal standard [16]. Ascorbic acid in deproteinised plasma samples was separated and quantified by reverse-phase HPLC using external standards $(0-227 \mu \mathrm{M})$. Ascorbic acid measurements were not corrected for recovery, which was $\sim 90 \%$. The inter-analysis precision coefficients of variation were $5.4 \%, 3 \%$ and $3.5 \%$ for ascorbic acid, $\alpha$ tocopherol and retinol, respectively. Bilirubin, uric acid, albumin and total cholesterol were measured using enzymatic methods on an automated biochemistry analyser.

For the Trolox equivalent antioxidant capacity (TEAC) assay [17], heparinised blood was centrifuged and the plasma stored at $-80^{\circ} \mathrm{C}$ until assayed within 2 weeks, using total antioxidant status kits according to the manufacturer's instructions (Randox Laboratories, Crumlin, UK). The assay was standardised using the water soluble vitamin E analogue, Trolox, with antioxidant capacities calculated as millimoles of Trolox equivalent per litre of plasma.

\section{Data analysis and statistics}

Dietary antioxidant intakes were adjusted for total energy intake (mg per $1000 \mathrm{kcal}$ per day) to control for variations in body size, physical activity and metabolic efficiency [18]. Plasma vitamin E concentrations were adjusted for lipid status by expression as the ratio vitamin E/total cholesterol [19]. Differences between mean values were assessed for statistical significance by analysis of variance followed by the Tukey or Bonferroni multiple comparison tests. Sex differences in plasma antioxidant concentrations were assessed by unpaired t-tests. The Mann-Whitney U-test was used to compare dietary antioxidant intakes, which were not normally distributed. Pearson correlation coefficients were determined, except when correlating plasma antioxidant levels with dietary intakes, when Spearman's correlation was used. Multivariate logistic regression was used to identify significant independent predictors for severe asthma, and multiple linear regression was used to analyse the relationship between lung function and plasma antioxidant concentrations. To reduce possible confounding vitamin supplement use, smoking and SES were included as covariates in the regression analyses.

\section{RESULTS \\ Demographic characteristics of asthmatic and control subjects}

The age and sex distributions of the control, mild-to-moderate and severe asthmatic subjects were similar, but body mass index (BMI) and total fat intake were greater in severe asthmatics and they were more likely to belong to the low and middle socioeconomic groups $(\mathrm{p}<0.05$, table 1$)$. There were more current smokers among the severe asthmatics and control subjects than among the mild-to-moderate asthmatics $(p=0.03)$. The patients were clearly differentiated into those with mild-to-moderate or severe asthma, as demonstrated by the mean data for FEV1, medication use and hospital admissions (tables 1 and 2).

\section{Dietary antioxidant intake}

Intakes of vitamins C, E, A and carotene did not differ significantly among mild-to-moderate asthmatics, severe asthmatics and control subjects. The mean energy intake of males $\left(2,760 \pm 294 \mathrm{kcal} \cdot \mathrm{day}^{-1}\right)$ was significantly

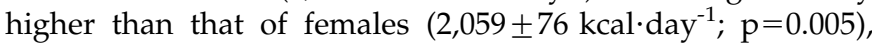
but after adjustment for total energy intake, vitamin $\mathrm{C}$ and carotene intakes were lower in all males compared with all females and also in severe asthmatic males compared with females (fig. 1). Furthermore, male patients with severe asthma had lower vitamin $C$ intakes when compared with both male and female mild-to-moderate asthmatic and control subjects. There were no sex differences in intakes of vitamins A or E. For all subjects, dietary intake of vitamin C was correlated with plasma ascorbic acid concentration $(\rho=0.41 ; \quad \mathrm{p}<0.001)$ and carotene intake was correlated with plasma $\beta$-carotene $(\rho=0.29 ; \mathrm{p}=0.001)$ and $\alpha$-carotene

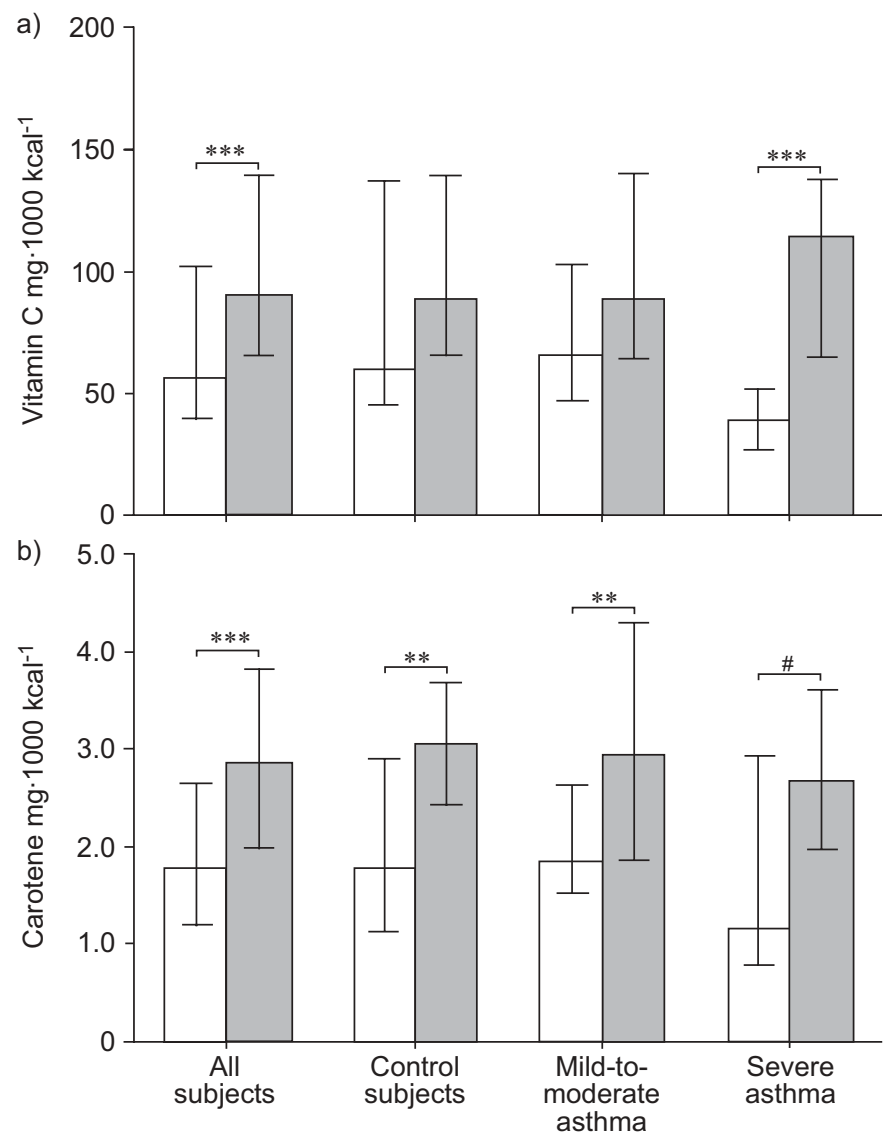

FIGURE 1. Intakes of a) vitamin C, and b) carotene in males ( $\square$ ) and females $(\square)$ in the different subject groups. Antioxidant intakes were corrected for tota energy intake and bars show median values with interquartile ranges. Vitamin C intake in severe asthmatic males was significantly less than that of both male $(p<0.05)$ and female $(p<0.002)$ control subjects and mild-to-moderate asthmatics **: $p<0.01 ; * * *: p<0.001 ; *: p<0.02$ 
concentrations $(\rho=0.33 ; \mathrm{p}<0.001)$. Consumption of vitamin supplements was more frequent among mild-to-moderate $(47.2 \%)$ than severe asthmatics $(21.4 \%, \mathrm{p}=0.03)$.

\section{Plasma concentrations of dietary antioxidants}

Plasma ascorbic acid was significantly lower in severe $(31.9 \pm 3.6 \mu \mathrm{M})$ compared with mild-to-moderate asthmatic $(52.3 \pm 2.6)$ or control subjects $(52.7 \pm 2.9$; fig. 2$)$. Sub-analyses indicated that these differences were significant even after exclusion of vitamin supplement users or current smokers (data not shown). Since vitamin E concentrations were strongly correlated with total cholesterol $(r=0.57 ; p<0.001)$, the values were adjusted in order to assess biologically functional vitamin E concentrations [19]. Lipid adjusted vitamin E concentrations in severe $\left(6.4 \pm 0.2 \mu \mathrm{mol} \mathrm{mmol}^{-1}\right.$ cholesterol $)$ and mild-tomoderate asthmatic patients $(6.6 \pm 0.2)$ were significantly lower than in control subjects $(7.4 \pm 0.4 ; \mathrm{p}<0.05)$. These differences were significant even after excluding current smokers from the analysis. Plasma ascorbic acid and vitamin E concentrations did not differ significantly in severe asthmatic patients who were using oral corticosteroids $(n=9)$ compared with those who were not $(n=19)$. Plasma vitamin $A, \beta$-carotene, $\alpha$ carotene and lycopene concentrations did not differ significantly among the groups.
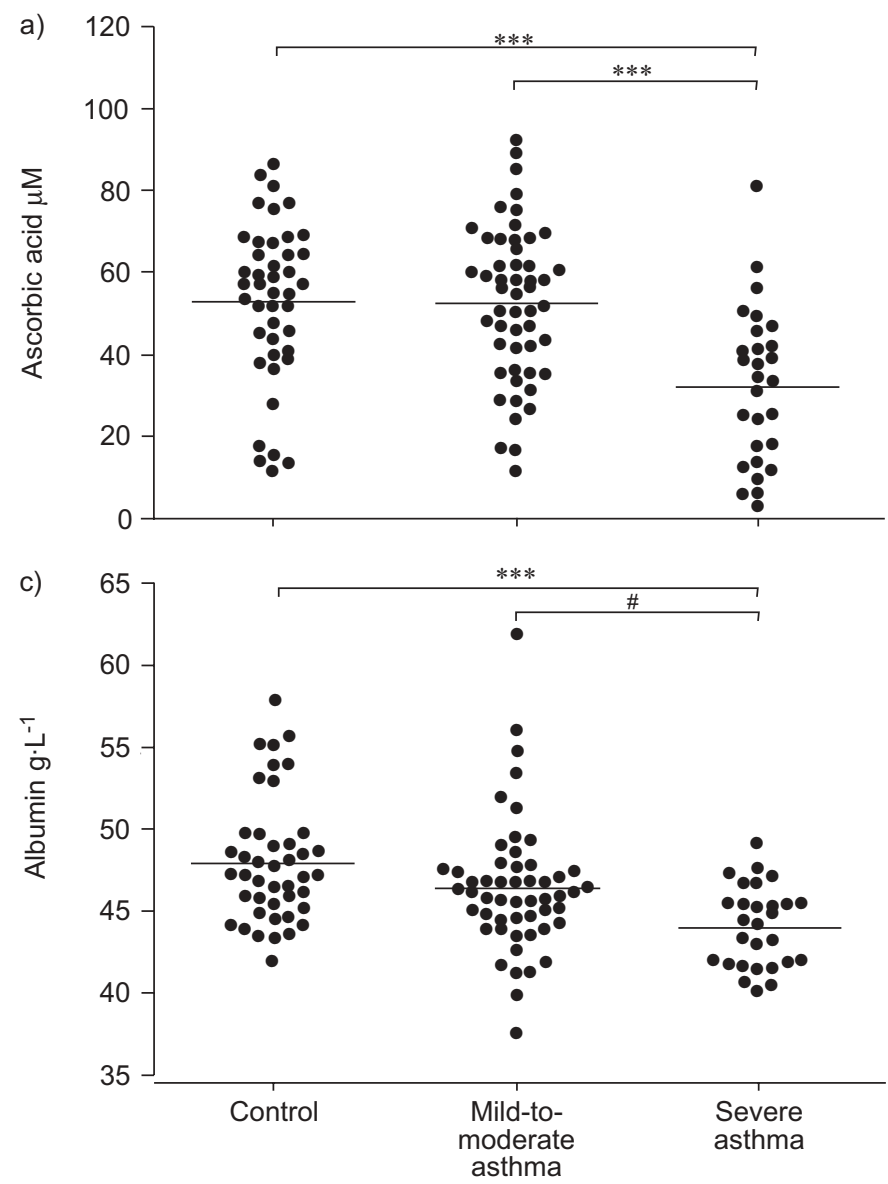

\section{Plasma concentrations of nondietary antioxidants}

Plasma bilirubin and albumin concentrations were lower, whereas total cholesterol concentration was higher in patients with severe asthma (fig. 2). Bilirubin, albumin and cholesterol concentrations were not different in severe asthmatic patients currently using oral corticosteroids compared with those who were not. There were no significant differences in plasma uric acid concentrations or TEAC, but these parameters were strongly correlated with each other $(r=0.6$; $\mathrm{p}<0.001)$.

\section{Sex differences in plasma antioxidant concentrations}

Plasma ascorbic acid concentration was significantly lower in all males $(39.9 \pm 3.1 \mu \mathrm{M})$ compared with all females $(52.3 \pm 2.2 ; \mathrm{p}<0.002)$, and also in males compared with females in both the control and severe asthmatic groups (fig. 3a). Importantly, for both males and females, severe asthmatics had lower ascorbic acid concentrations compared with mild-to-moderate asthmatic and control subjects. Even after exclusion of vitamin supplement users, ascorbic acid was lower in all males compared with all females, and in severe compared with mild-to-moderate asthmatic males and females (data not shown). In contrast, TEAC and uric acid concentrations were higher in male compared with female

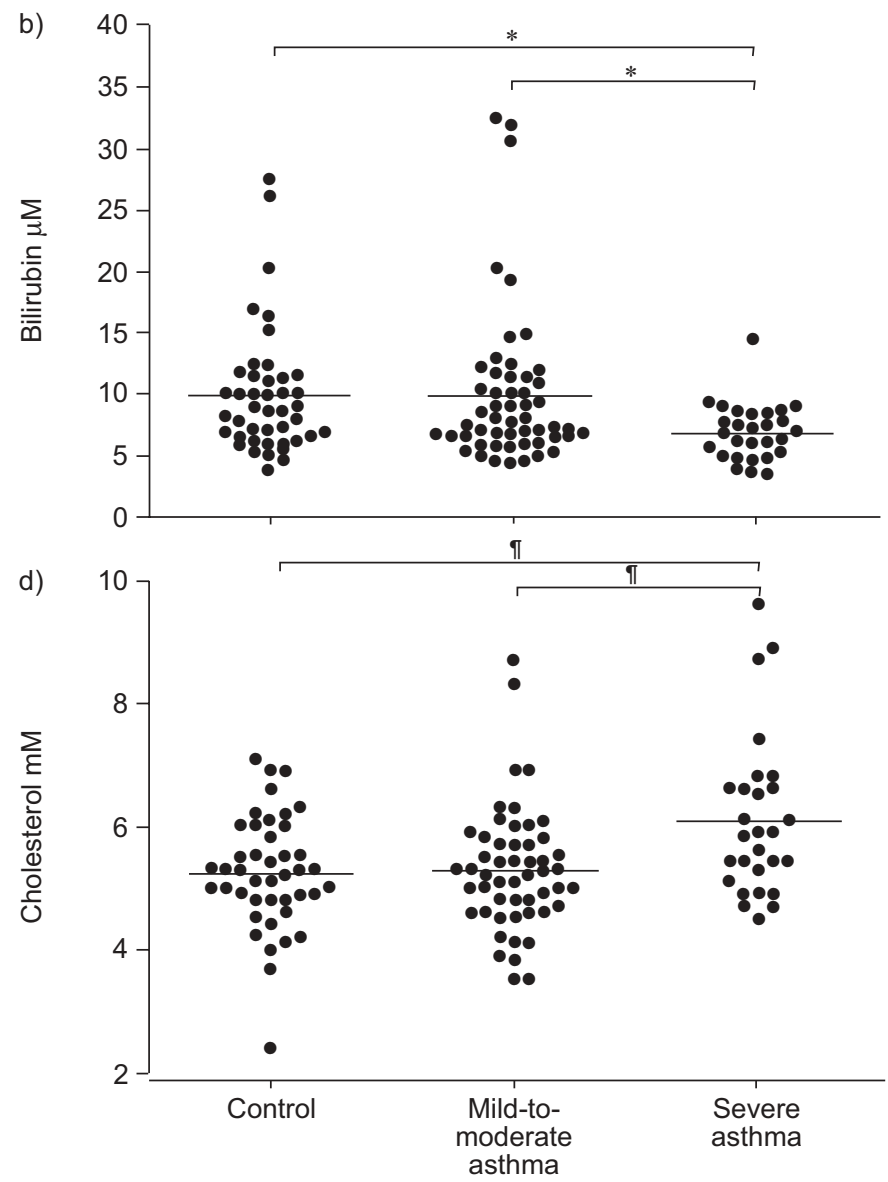

FIGURE 2. Plasma concentrations of a) ascorbic acid, b) bilirubin, c) albumin and d) cholesterol in control subjects ( $n=43$ ) and patients with mild-to-moderate ( $n=53$ ) or severe asthma $(n=28)$. Horizontal bars indicate mean values. ${ }^{*}: p<0.05$; ${ }^{* *}: p<0.001 ;{ }^{*}: p<0.02 ; ": p<0.005$. 

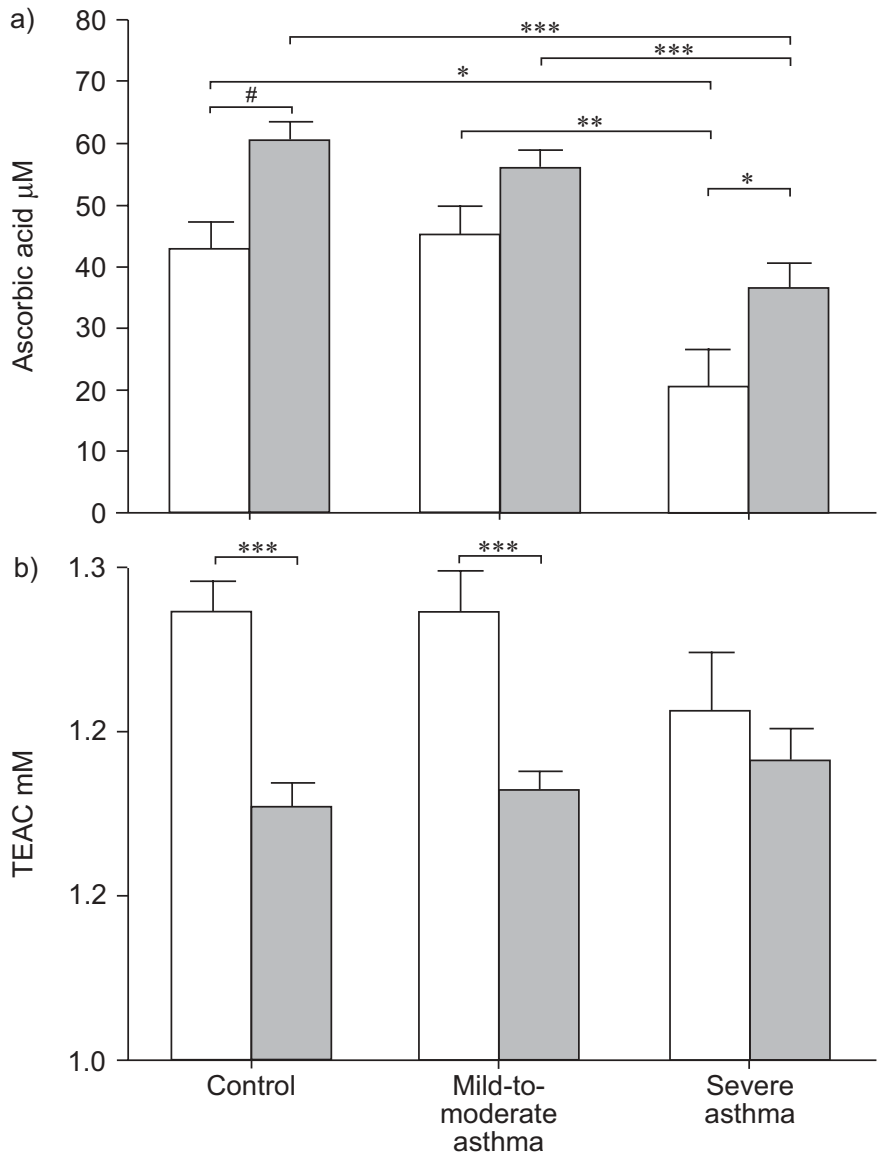

FIGURE 3. Mean \pm SEM of a) plasma ascorbic acid concentrations and b) Trolox equivalent antioxidant capacity (TEAC) in male ( $\square$ ) and female ( $\square$ ) control subjects $(n=43)$ and patients with mild-to-moderate $(n=53)$ or severe asthma $(n=28) .{ }^{*}: p<0.05 ;{ }^{* *}: p<0.01 ;{ }^{* *}: p<0.001 ; *: p<0.002$.

control and mild-to-moderate asthmatic subjects (fig. 3b). There were no sex differences in the plasma concentrations of other antioxidants.

\section{Association of plasma antioxidants with severe asthma and lung function}

Multivariate logistic regression indicated that lower plasma ascorbic acid and bilirubin concentrations, low SES and higher cholesterol concentration were independent predictors of severe asthma (table 3). On univariate analysis, FEV1 \% predicted for all subjects was positively correlated with plasma albumin, ascorbic acid and bilirubin, and negatively correlated with cholesterol (fig. 4). Multiple linear regression analysis indicated independent positive correlations of percentage predicted FEV1 with plasma albumin and vitamin supplement use, and a negative correlation with plasma cholesterol (table 4).

\section{DISCUSSION}

Epidemiological studies suggest that decreased antioxidant intake is associated with an increased prevalence of asthma $[3,12]$, although it is not known whether it is also associated with the development of more severe asthma. The present study has identified low plasma ascorbic acid concentration

\begin{tabular}{|c|c|c|}
\hline \multirow[t]{2}{*}{ TABLE 3} & \multirow[b]{2}{*}{ Odds ratio $(95 \% \mathrm{Cl})^{\#}$} & $\begin{array}{l}\text { tors associated } \\
\text {-moderate }\end{array}$ \\
\hline & & Significance \\
\hline \multirow{4}{*}{$\begin{array}{l}\text { Vitamin } \mathbf{C} \mu \mathrm{M} \\
\text { Socioeconomic status } \\
\text { Bilirubin } \mu \mathrm{M} \\
\text { Total cholesterol } \mathrm{mM}\end{array}$} & $0.934(0.898-0.972)$ & $p=0.001$ \\
\hline & $0.282(0.107-0.743)$ & $p=0.01$ \\
\hline & $0.691(0.514-0.929)$ & $p=0.014$ \\
\hline & $1.975(1.045-3.732)$ & $p=0.036$ \\
\hline \multicolumn{3}{|c|}{$\begin{array}{l}\mathrm{Cl} \text { : confidence interval. \#: indicates change in risk per unit of antioxidant or } \\
\text { category of socioeconomic status. The backward stepwise logistic regression } \\
\text { analysis included the following covariates in the model: age, sex, body mass } \\
\text { index, socioeconomic status ( } 1=\text { low, } 2=\text { middle and } 3=\text { high, based on the } \\
\text { patient's residential postcode), atopic and smoking status, vitamin supplement } \\
\text { use and the plasma concentrations of all antioxidants and cholesterol. }\end{array}$} \\
\hline
\end{tabular}

as an independent predictor of more severe asthma. The difference in mean plasma ascorbic acid concentration of $\sim 20 \mu \mathrm{M}$ between severe and mild-to-moderate asthmatic patients is likely to have biologically important consequences. Previous studies have reported that an increase in plasma ascorbic acid of similar magnitude is associated with a 20 $30 \mathrm{~mL}$ improvement in FEV1 in normal subjects $[5,20]$ and with a $20 \%$ reduction in the risk of all-cause mortality [21]. Decreased plasma ascorbic acid in severe asthma may reflect increased oxidative stress and an increased transfer of ascorbic acid to the epithelial lining fluid of the lungs where it scavenges reactive oxygen and nitrogen species [2].

Low ascorbic acid concentrations have previously been reported in the serum of patients with asthma $[22,23]$ and adult onset wheeze [10], and also in the respiratory tract lining fluid of mild asthmatic patients [24]. Recent studies have also shown associations between low serum ascorbic acid and increased risk or prevalence of asthma among children and adolescents $[25,26]$. However, other studies have reported no differences in bronchoalveolar lavage fluid or serum vitamin $C$ concentration in asthmatic compared with nonasthmatic children [27], and serum ascorbate levels were not low in subjects with brittle asthma [28]. In the only previous study that has investigated plasma ascorbic acid in relation to asthma severity, no association was found [29]. These conflicting results may be partly explained by differences in the patients studied, or the possibility of a stronger association between ascorbic acid and asthma severity if there is also a deficiency of other antioxidants such as selenium, as observed in the current authors' previous study of West Australian asthmatic patients [11].

Tobacco smoke, even when passively inhaled, decreases plasma ascorbic acid [30], and differences in vitamin supplement use between the groups may also potentially have influenced the results. Although there were more smokers and fewer supplement users among the severe asthmatic patients, the number of smokers in all groups was small and lower plasma ascorbate concentrations were associated with more severe asthma even after exclusion of smokers or supplement users. Therefore, confounding due to the effects of smoking or vitamin supplement use is unlikely, and the present results 

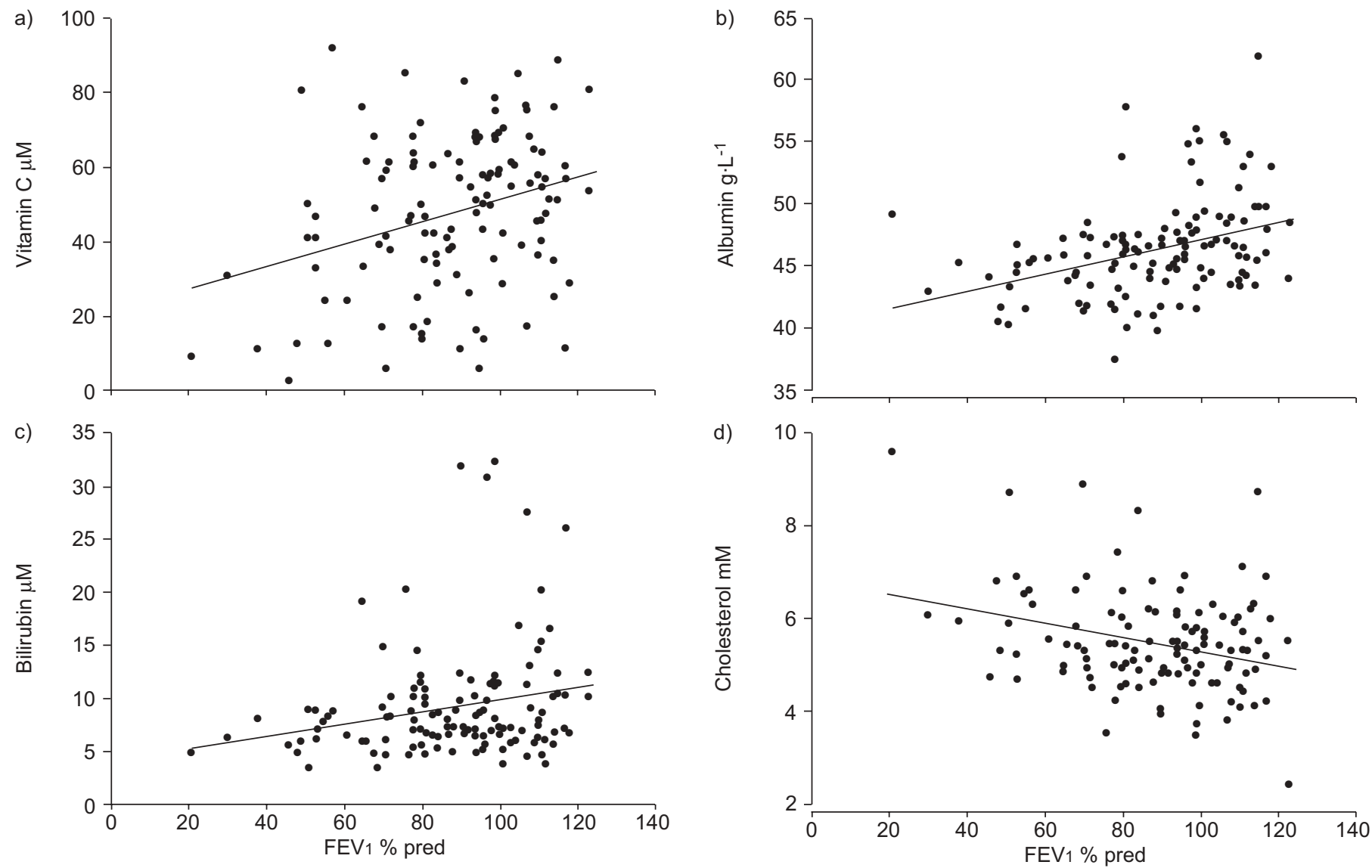

FIGURE 4. Univariate correlations between lung function (forced expiratory volume in one second (FEV1) \% pred) for all subjects and plasma concentrations of a) ascorbic acid, b) bilirubin, c) albumin and d) cholesterol. Data were analysed using Pearson's correlation coefficient (r). a) $r=0.30, p<0.001 ; b) r=0.36, p<0.0001 ; c) r=0.22$, $p=0.013 ;$ and d) $r=-0.29, p=0.001$.

\begin{tabular}{|c|c|c|c|}
\hline \multirow[t]{2}{*}{ TABLE 4} & \multirow[b]{2}{*}{$\begin{array}{c}\text { Regression } \\
\text { coefficient } \\
(95 \% \mathrm{Cl})\end{array}$} & \multirow[b]{2}{*}{$\begin{array}{c}\text { Standardised } \\
\text { regression } \\
\text { coefficient }\end{array}$} & \multirow[b]{2}{*}{ Significance } \\
\hline & & & \\
\hline Albumin & $1.93(1.1-2.77)$ & 0.363 & $p<0.001$ \\
\hline Cholesterol & $-5.25(-8.25--2.25)$ & -0.275 & $p=0.001$ \\
\hline Vitamin supplement use & $8.27(1.63-14.91)$ & 0.196 & $p=0.015$ \\
\hline
\end{tabular}

Cl: confidence interval. The backward stepwise linear regression analysis with forced expiratory volume in one second \% predicted for all subjects as the dependent variable included the following independent variables in the model: age, sex, body mass index, socioeconomic status, atopic and smoking status, vitamin supplement use and the plasma concentrations of all antioxidants and cholesterol.

suggest a real association between lower plasma ascorbic acid concentrations and more severe asthma.

Lower plasma ascorbic acid and carotene concentrations in males may reflect a particularly low intake of these nutrients, with potentially deleterious consequences for males with severe asthma. Although vitamin $\mathrm{C}$ intake was higher in females with severe asthma, plasma levels were still low suggesting that increased oxidative stress may not be fully compensated even by a relatively adequate dietary antioxidant intake. A less healthy diet, inadequate utilisation of medical services and poorer treatment compliance may all have contributed to the association between lower SES and more severe asthma. Interestingly, recent studies have shown that increased intakes of antioxidant containing foods, including apples, pears, selenium and red wine may protect against asthma [31, 32].

Supplementation with vitamin $C$ may have beneficial effects on lung function in asthmatic children [33], although a recent trial found no additional clinical benefit from vitamin $\mathrm{C}$ in patients with mild, well controlled asthma [34]. Nevertheless, the results of the present study, together with recent evidence that the beneficial effects of antioxidants may be influenced by polymorphisms in the glutathione S-transferase gene [35], indicate that there is a need for further trials of vitamin $C$ supplementation in patients with more severe asthma.

Low plasma concentrations of both ascorbic acid and vitamin $\mathrm{E}$ in this and other studies [10,24], support the possibility of a physiological interaction between these antioxidants [36]. 
Vitamin E also has roles in immunomodulation, signalling and transcriptional regulation. Small decreases in the availability of vitamin E could have important consequences in the lungs [37], as suggested by studies showing beneficial effects of increased vitamin E intake, particularly in children [33, 38, 39]. However, a recent placebo-controlled study of vitamin E supplementation showed no evidence of clinical benefit in asthma [40].

Albumin, the most abundant plasma protein, is an important extracellular antioxidant regulating glutathione levels in lung epithelial cells [41, 42]. Bilirubin protects albumin from oxidative damage and acts in concert with vitamin $\mathrm{E}$ to inhibit the oxidation of low density lipoprotein [43]. The potential importance of these nondietary antioxidants is emphasised by the current observations that plasma albumin correlated positively with lung function, while plasma bilirubin was inversely associated with severe asthma. Low plasma bilirubin and albumin levels may influence asthma severity by adversely affecting antioxidant capacity and the regulation of lung epithelial cell glutathione content [42]. Plasma albumin levels have also been reported to be lower in corticosteroiddependent asthmatic patients [44], possibly as a consequence of disease activity or corticosteroid treatment. However, the present data did not indicate an effect of current oral corticosteroid use on plasma bilirubin or albumin concentrations.

TEAC levels were unaltered in patients with severe asthma, supporting other evidence that low plasma antioxidant concentrations or increased oxidative stress are not reflected in altered total antioxidant capacity in asthmatic patients [10, 45]. Low levels of specific antioxidants may be masked by increases in another antioxidant such as uric acid, which has a greater relative contribution in the TEAC assay [46]. Thus, in mild asthma, bronchial lavage fluid uric acid concentrations were increased, possibly to compensate for low ascorbic acid and vitamin E concentrations [24]. The lower TEAC values in females probably reflect the strong correlation between TEAC and plasma uric acid, which is known to be lower in females.

Serum concentrations of ascorbic acid, vitamin E and carotenoids are positively associated with lung function in the general population [5,20], and in the current study ascorbic acid, bilirubin and albumin were positively correlated with percentage predicted FEV1 on univariate analysis. In multivariate regression, albumin and use of vitamin supplements showed positive correlations, while cholesterol showed a negative correlation with lung function. The positive correlation between vitamin supplement use and lung function and the lower utilisation of supplements by severe asthmatics provides further evidence that reduced antioxidant intake may have adverse consequences for respiratory function in these patients. The higher cholesterol concentrations in severe asthma and the negative correlation between lung function and cholesterol were unexpected findings, but taken together with the current observation that fat intake and BMI were increased in the severe asthmatic patients, tend to support recent evidence of an association between obesity and asthma $[47,48]$.
In conclusion, the results of the present study suggest that low levels of specific plasma antioxidants are associated with the severity of asthma, particularly in males. The cross-sectional design of the study does not permit a definitive answer to the question of whether the observed differences in antioxidant concentrations are a cause or consequence of the severe asthma phenotype. However, the authors' results suggest a need for further large case-control and cohort studies, followed by prospective studies to determine whether dietary modification or supplementation with antioxidants such as vitamin $C$ will be of benefit in reducing the social and economic burden of severe asthma.

\section{ACKNOWLEDGEMENTS}

The authors would like to thank R. Littleford (Asthma \& Allergy Research Institute, Nedlands) and J. Beilby (Clinical Biochemistry, PathCentre, Nedlands, Western Australia) for their assistance.

\section{REFERENCES}

1 Wood LG, Gibson PG, Garg ML. Biomarkers of lipid peroxidation, airway inflammation and asthma. Eur Respir J 2003; 21: 177-186.

2 Cross CE. The antioxidant milieu at asthmatic respiratory tract surfaces. Pediatr Res 2003; 53: 365-368.

3 Seaton A, Godden DJ, Brown K. Increase in asthma: a more toxic environment or a more susceptible population. Thorax 1994; 49: 171-174.

4 Fogarty A, Britton J. The role of diet in the aetiology of asthma. Clin Exp Allergy 2000; 30: 615-627.

$5 \mathrm{Hu} \mathrm{G}$, Cassano P. Antioxidant nutrients and pulmonary function: the third National Health and Nutrition Examination Survey (NHANES III). Am J Epidemiol 2000; 151: 975-981.

6 Hu G, Zhang X, Chan J, Peto R, Campbell TC, Cassano PA. Dietary vitamin $C$ intake and lung function in rural China. Am J Epidemiol 1998; 148: 594-599.

7 Grievink L, Smit HA, Ocke MC, van't Veer P, Kromhout D. Dietary intake of antioxidant (pro)-vitamins, respiratory symptoms and pulmonary function: the MORGEN study. Thorax 1998; 53: 166-171.

8 Britton JR, Pavord ID, Richards KA, et al. Dietary antioxidant vitamin intake and lung function in the general population. Am J Respir Crit Care Med 1995; 151: 1383-1387.

9 Rahman I, Morrison D, Donaldson K, MacNee W. Systemic oxidative stress in asthma, COPD, and smokers. Am J Respir Crit Care Med 1996; 154: 1055-1060.

10 Bodner C, Godden D, Brown K, Little J, Ross S, Seaton A. Antioxidant intake and adult-onset wheeze: a case-control study. Eur Respir J 1999; 13: 22-30.

11 Misso NLA, Powers KA, Gillon RL, Stewart GA, Thompson PJ. Reduced platelet glutathione peroxidase activity and serum selenium concentration in atopic asthmatic patients. Clin Exp Allergy 1996; 26: 838-847.

12 McKeever TM, Britton J. Diet and asthma. Am J Respir Crit Care Med 2004; 170: 725-729.

13 National Institutes of Health. National Asthma Education and Prevention Program Expert Panel Report II. Guidelines for the diagnosis and management of asthma. NIH Publication No. 97-4051. Bethesda, MD, 1997. 
14 Hyndman JC, Holman CD, Hockey RL, Donovan RJ, Corti B, Rivera J. Misclassification of social disadvantage based on geographical areas: comparison of postcode and collector's district analyses. Int J Epidemiol 1995; 24: 165-176.

15 Wheeler CE, Rutishauser IHE. Comparison of nutrient intake data from two food frequency questionnaires and weighed records. Aust J Nutr Diet 1995; 52: 140-148.

16 Thurnham DI, Smith E, Flora PS. Concurrent liquid chromatographic assay of retinol, alpha-tocopherol, betacarotene, alpha-carotene, lycopene, and beta-cryptoxanthin in plasma with tocopherol acetate as internal standard. Clin Chem 1988; 34: 377-381.

17 Miller NJ, Rice-Evans CA, Davies MJ, Gopinathan V, Milner A. A novel method for measuring antioxidant capacity and its application to monitoring the antioxidant status in premature neonates. Clin Sci 1993; 84: 407-412.

18 Willett WC, Howe GR, Kushi LH. Adjustment for total energy intake in epidemiologic studies. Am J Clin Nutr 1997; 65: Suppl. 4, 1220S-1228S.

19 Traber MG, Jialal I. Measurement of lipid-soluble vitamins - further adjustment needed? Lancet 2000; 355: 2013-2014.

20 Schünemann HJ, Grant BJB, Freudenheim JL, et al. The relation of serum levels of antioxidant vitamins $C$ and $E$, retinol and carotenoids with pulmonary function in the general population. Am J Respir Crit Care Med 2001; 163: 1246-1255.

21 Khaw K-T, Bingham S, Welch A, et al. Relation between plasma ascorbic acid and mortality in men and women in EPIC-Norfolk prospective study: a prospective population study. Lancet 2001; 357: 657-663.

22 Olusi SO, Ojutiku OO, Jessop WJE, Iboko MI. Plasma and white blood cell ascorbic acid concentrations in patients with bronchial asthma. Clin Chim Acta 1979; 92: 161-166.

23 Ford ES, Mannino DM, Redd SC. Serum antioxidant concentrations among U.S. adults with self-reported asthma. J Asthma 2004; 41: 179-187.

24 Kelly FJ, Mudway I, Blomberg A, Frew A, Sandstrom T. Altered lung antioxidant status in patients with mild asthma. Lancet 1999; 354: 482-483.

25 Rubin RN, Navon L, Cassano PA. Relationship of serum antioxidants to asthma prevalence in youth. Am J Respir Crit Care Med 2004; 169: 393-398.

26 Harik-Khan RI, Muller DC, Wise RA. Serum vitamin levels and the risk of asthma in children. Am J Epidemiol 2004; 159: 351-357.

27 Schock BC, Young IS, Brown V, Fitch PS, Shields MD, Ennis M. Antioxidants and oxidative stress in BAL fluid of atopic asthmatic children. Pediatr Res 2003; 53: 375-381.

28 Baker JC, Tunnicliffe WS, Duncanson RC, Ayres JG. Dietary antioxidants and magnesium in type 1 brittle asthma: a case control study. Thorax 1999; 54: 115-118.

29 Picado C, Deulofeu R, Lleonart R, et al. Dietary micronutrients/antioxidants and their relationship with bronchial asthma severity. Allergy 2001; 56: 43-49.

30 Dietrich M, Block G, Norkus EP, et al. Smoking and exposure to environmental tobacco smoke decrease some plasma antioxidants and increase $\gamma$-tocopherol in vivo after adjustment for dietary antioxidant intakes. Am J Clin Nutr 2003; 77: 160-166.
31 Shaheen SO, Sterne JA, Thompson RL, Songhurst CE, Margetts BM, Burney PG. Dietary antioxidants and asthma in adults: population-based case-control study. Am J Respir Crit Care Med 2001; 164: 1823-1828.

32 Woods RK, Walters EH, Raven JM, et al. Food and nutrient intakes and asthma risk in young adults. Am J Clin Nutr 2003; 78: 414-421.

33 Romieu I, Sienra-Monge JJ, Ramírez-Aguilar M, et al. Antioxidant supplementation and lung functions among children with asthma exposed to high levels of air pollutants. Am J Respir Crit Care Med 2002; 166: 703-709.

34 Fogarty A, Lewis SA, Scrivener SL, et al. Oral magnesium and vitamin $C$ supplements in asthma: a parallel group randomized placebo-controlled trial. Clin Exp Allergy 2003; 33: $1355-1359$.

35 Romieu I, Sienra-Monge J, Ramirez-Aguilar $\mathrm{M}$, et al. Genetic polymorphism of GSTM1 and antioxidant supplementation influence lung function in relation to ozone exposure in asthmatic children in Mexico City. Thorax 2004; 59: 8-10.

36 Hamilton IM, Gilmore WS, Benzie IF, Mulholland CW, Strain JJ. Interactions between vitamins $\mathrm{C}$ and $\mathrm{E}$ in human subjects. Br J Nutr 2000; 84: 261-267.

37 Kolleck I, Sinha P, Rüstow B. Vitamin E as an antioxidant of the lung: mechanisms of vitamin E delivery to alveolar type II cells. Am J Respir Crit Care Med 2002; 166: S62-S66.

38 Fogarty A, Lewis S, Weiss S, Britton J. Dietary vitamin E, IgE concentrations, and atopy. Lancet 2000; 356: 1573-1574.

39 Hijazi N, Abalkhail B, Seaton A. Diet and childhood asthma in a society in transition: a study in urban and rural Saudi Arabia. Thorax 2000; 55: 775-779.

40 Pearson PJ, Lewis SA, Britton J, Fogarty A. Vitamin E supplements in asthma: a parallel group randomised placebo controlled trial. Thorax 2004; 59: 652-656.

41 Halliwell B. Albumin - an important extracellular antioxidant? Biochem Pharmacol 1988; 37: 569-571.

42 Cantin AM, Paquette B, Richter M, Larivee P. Albuminmediated regulation of cellular glutathione and nuclear factor kappa B activation. Am J Respir Crit Care Med 2000; 162: 1539-1546.

43 Neuzil J, Stocker R. Free and albumin-bound bilirubin are efficient co-antioxidants for alpha-tocopherol, inhibiting plasma and low density lipoprotein lipid peroxidation. J Biol Chem 1994; 269: 16712-16719.

44 Picado C, Deulofeu R, Lleonart R, et al. Lipid and protein metabolism in asthma. Effects of diet and corticosteroid therapy. Allergy 1999; 54: 569-575.

45 Nadeem A, Chhabra SK, Masood A, Raj HG. Increased oxidative stress and altered levels of antioxidants in asthma. J Allergy Clin Immunol 2003; 111: 72-78.

46 Cao G, Prior RL. Comparison of different analytical methods for assessing total antioxidant capacity of human serum. Clin Chem 1998; 44: 1309-1315.

47 Tantisira KG, Weiss ST. Complex interactions in complex traits: obesity and asthma. Thorax 2001; 56: Suppl. 2, ii64-ii74.

48 Ford ES, Mannino DM, Redd SC, Mokdad AH, Mott JA. Body mass index and asthma incidence among USA adults. Eur Respir J 2004; 24: 740-744. 